\title{
Forecasting Damage Length of Maritime Structures Caused by Typhoons Based on Improved EWE Method
}

\author{
R. Hashimura
}

\begin{abstract}
The aim is to forecast the damage length of damaged maritime structures at each coast for each pass of a typhoon of the equivalent wave energy of a typhoon at a latitude of $30^{\circ} \mathrm{N}$ using the so-called equivalent wave energy (EWE) method, which has been improved. EWE of typhoons is defined based on the maximum wind speed and the duration of wind blowing of the typhoon. Using the data on the damage length of maritime structures by typhoons and the path and the equivalent wave energy of typhoons, the vulnerability of coastal regions along the coastline of Japan for 13 groups of typhoon with different paths is estimated. The improved EWE method has been upgraded in comparison with EWE method and it will be used to estimate the damage length of damaged maritime structures that will occur along the coast at a latitude of $30^{\circ} \mathrm{N}$ before a typhoon strikes. The forecasting method reported here will be used for the purpose of coastal zone management in disaster prevention works. Further, it provides useful for information of storm warning and evacuation of residents along coastlines.
\end{abstract}

Index Terms-Equivalent wave energy method, damage length, typhoon vulnerability.

\section{INTRODUCTION}

This paper deals with the damage of maritime structures caused by the typhoons in the harbors and coastal areas along the coasts in Kumamoto prefecture on Kyushu Island of Japan (Fig. 1 and Fig. 2). The damage of structures means the breaching of dikes, cracking of seawalls, overturning of break waters, shift of breakwaters, removal of rubble from groins, etc. The damage length is defined as a summation of the alongshore length of the parts of structures damaged by a typhoon.

In Kumamoto Prefecture the coasts face closed and open sea areas. The closed sea areas are the Ariake and Yatsushiro Seas. The open sea area is the East China Sea. In this paper, we divided the coastline into 4 coastal regions. Each coastal region has different topographical characteristics (Fig. 2). The coasts facing the closed sea areas are the Ariake east (Ar. E.), Yatsushiro east (Yt. E.) and Yatsushiro west (Yt. W.) coasts. The coast facing the open sea area is the Amakusa west (Ak. W.) coast.

Typhoons which pass through Kyushu Island have many tracks. All typhoons dealt with in this paper had passed an area delineated by a latitude of $30^{\circ} \mathrm{N}$ and $35^{\circ} \mathrm{N}$ and a longitude of $127^{\circ} \mathrm{E}$ and $132^{\circ} \mathrm{E}$ (Fig. 3) in the past 25 years from 1980 to 2004. The number of typhoons passing through

Manuscript received November 15, 2012; revised January 20, 2013.

R. Hashimura is with the Department of EcoDesign, Sojo University, Kumamoto, Kumamoto Prefecture 860-0082, Japan (e-mail: ryusuke@eco.sojo-u.ac.jp). the delineated area is 74

The author already examined a relationship between the maximum wind speed near the center of a typhoon at alatitude of $30^{\circ} \mathrm{N}$ and the damage length caused by typhoon [1], [2]. This method was previously called the MWS method. This method is used to forecast the damage length by giving the path and the maximum wind speed of the typhoon based on 43 typhoons over 15 years from 1980 until 1994 at a latitude of $30^{\circ} \mathrm{N}$. The magnitude method was introduced as a new step of the MWS method [3], [4]. The magnitude method is defined based on the maximum wind speed and the size of typhoon. After that, the equivalent wave energy (EWE) method was introduced as a new step of the magnitude method [5]. The equivalent wave energy method is defined based on the maximum wind speed and the duration of wind blowing of a typhoon.

Furthermore, the author proposed an improved MWS method and an improved magnitude method that are calculated based on 74 typhoons over 25 years from 1980 until 2004 [6]-[8].

Additionally, in this paper, an improved Equivalent Wave Energy (iEWE) method, which is calculated based on 74 typhoons, is proposed for forecasting the damage length caused by a coming typhoon in each coast. The vulnerability and the damage length of maritime structures at each coast for the historical path of a typhoon, which is shown in Fig. 4, are estimated.

\section{13 GROUPS OF TYPHOON}

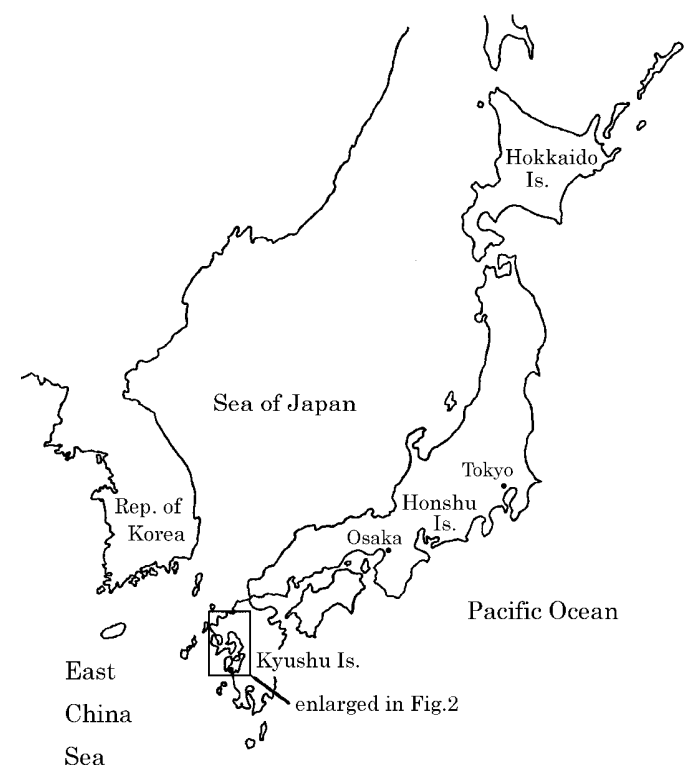

Fig. 1. Location of Kyushu Island of Japan. 


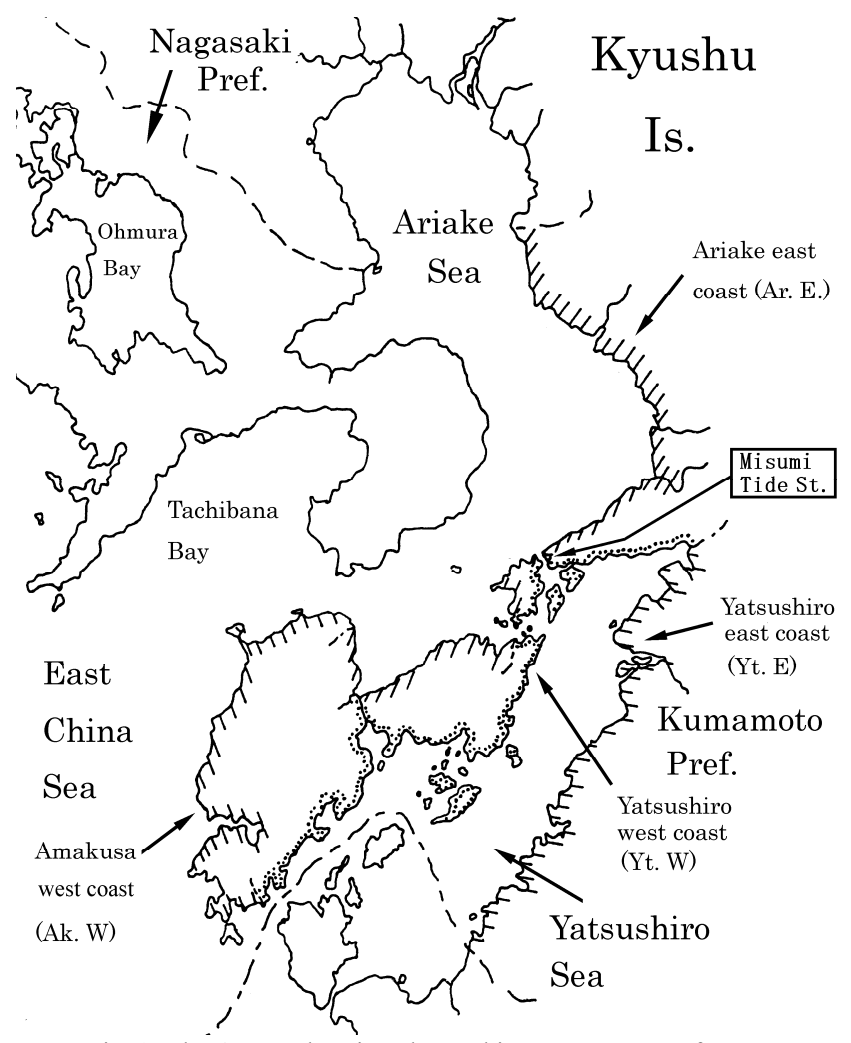

Fig. 2. The 4 coastal regions located in Kumamoto Prefecture.

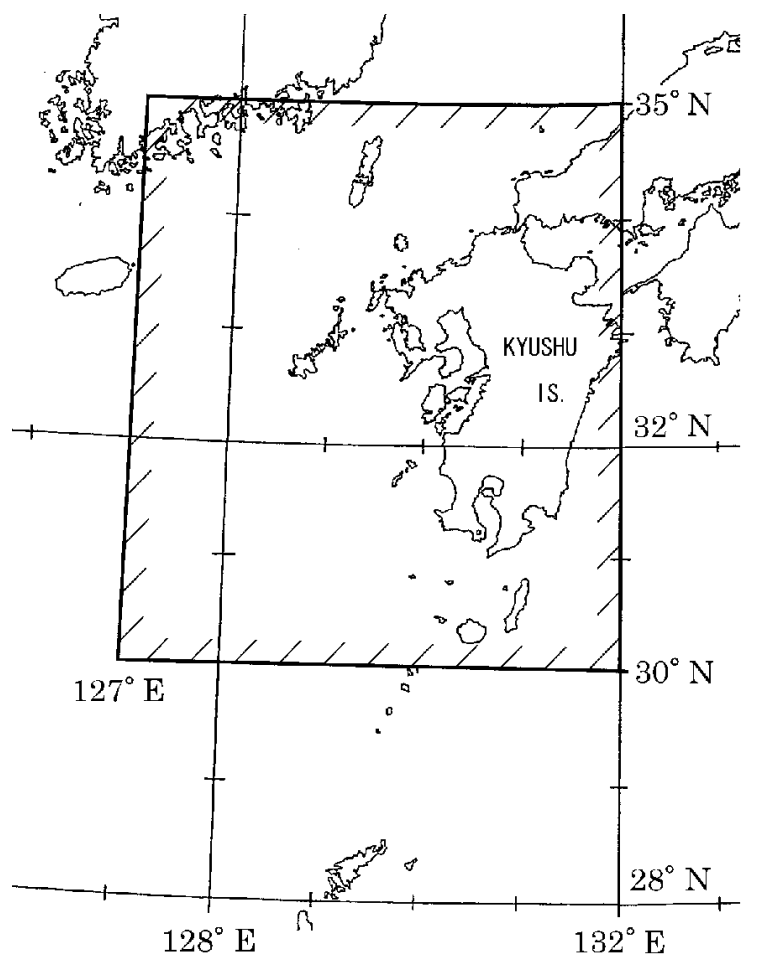

Fig. 3. Delineated area including Kyushu Island

The 74 typhoons, which passed through an area delineated by a latitude of $30^{\circ} \mathrm{N}$ and $35^{\circ} \mathrm{N}$ and a longitude of $127^{\circ} \mathrm{E}$ and $132^{\circ} \mathrm{E}$ (Fig. 3), between 1980 and 2004 are analyzed. The above mentioned delineated area was determined judging from the possibility of damage of the maritime structures along the coasts in Kumamoto Prefecture.

The typhoons between 1980 and 2004 were divided into 13 groups based on their paths (Fig. 4). The circled numbers in Fig. 4 indicates 13 storm paths for the 74 typhoons. The typhoons which did not follow any of these 13 groups are neglected.

In this paper, the author estimates the damage length of maritime structures on the coasts from the equivalent wave energy of a typhoon at a latitude of $30^{\circ} \mathrm{N}$. The typhoon of each path has a different direction of movement and the east longitude of the position at a latitude of $30^{\circ} \mathrm{N}$. The reason why 30 degrees north latitude is selected is that the direction of movement of a typhoon is roughly fixed and the scale of the typhoon becomes stable there.

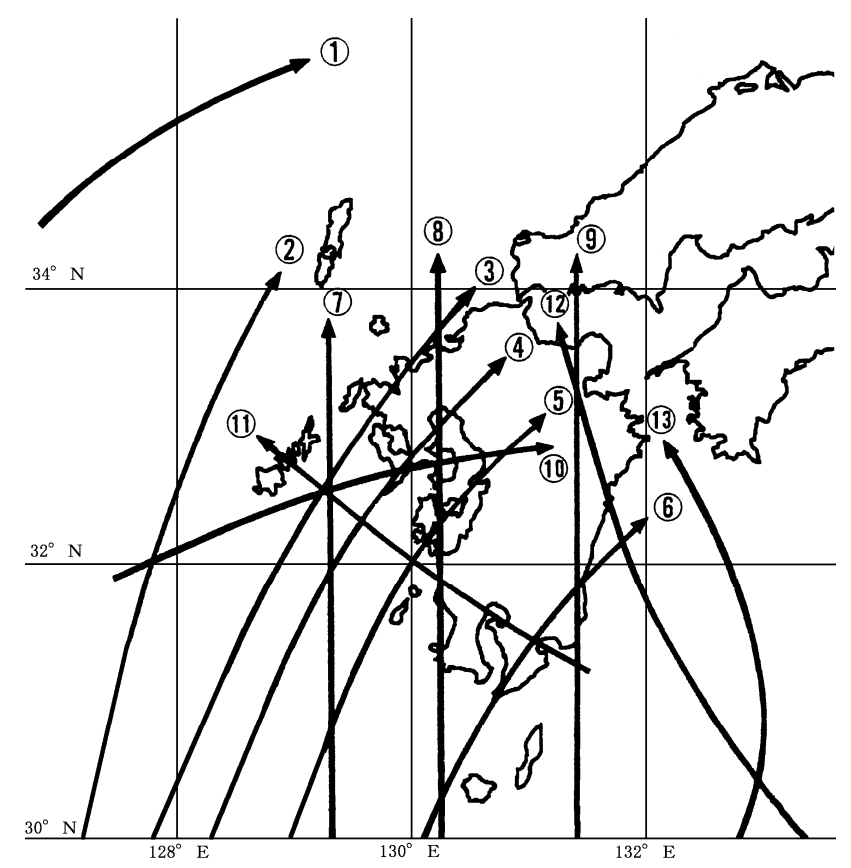

Fig. 4. Historical typhoon paths.

\section{EQUivalent WAVE ENERGY}

Considering the effect of waves on the maritime structure damage, not only the wave height, $\mathrm{H}$, but also the wave period, T, is important [9]. The maximum wind speed and the duration of strong winds are closely related to the typhoon's energy and its transfer. Wind waves gain their energy from the typhoon energy, and the wave height and period increase in the process of the typhoon energy transfer.

In this paper, the damage length of maritime structures on the coasts and the harbors is estimated based on the equivalent wave energy of a typhoon. The equivalent wave energy is defined as $\mathrm{H}^{2} \mathrm{~T}^{2}$. It is determined based on the duration time of the wind blowing and the maximum wind speed near the center of a typhoon. To determine the wind speed and its duration, different areas are specified for each path (Table I). The areas were determined considering the effectiveness of waves on the maritime structures along the coasts in Kumamoto Prefecture.

By observing the maximum wind speed $V_{\max , i}$ in a typhoon at time $\mathrm{t}_{\mathrm{i}}$ and the maximum wind speed $V_{\max , i+1}$ at time $t_{i+1}$ $\left(=t_{i}+\Delta t\right)$, the average maximum wind speed $V_{\max }$, ave is defined by (1)

$$
\begin{aligned}
V_{\text {max }, a v e}= & {\left[\sum\left\{\left(V_{\max , i+1}+V_{\max , i}\right) / 2\right\}\right.} \\
& \left.\times\left(t_{i+1}-t_{i}\right)\right] / \sum\left(t_{i+1}-t_{i}\right)
\end{aligned}
$$

The maximum wind speed near the center of a typhoon at a 
standard observatory time is periodically observed every one, three or six hours by the Japan Meteorological Agency (JMA). The time $t_{1}$ is adjusted at the observatory time when the typhoon passes through at a latitude of $30^{\circ} \mathrm{N}$. $t_{n}$ is the time when the typhoon passes out from the specified area (Table 1) for each typhoon path. The duration, $t$, is determined by $\mathrm{t}_{\mathrm{n}}-\mathrm{t}_{1}$.

Next, the significant wave height, $\mathrm{H}_{1 / 3}$, and period, $\mathrm{T}_{1 / 3}$, are determined from the wave forecasting curves based on the SMB method by using the duration, $t$, and average maximum wind speed, $\mathrm{V}_{\max \text {, ave, }}$ calculated by (1). The equivalent wave energy, $\mathrm{E}$, is calculated as $\mathrm{H}_{1 / 3}{ }^{2} \mathrm{~T}_{1 / 3}{ }^{2}$, the equi-value lines of which are shown in the wave forecasting curves based on the SMB method.

\begin{tabular}{cc} 
TABLE I: SPECIFIED AREA TO ESTIMATE EQUIVALENT WAVE ENERGY \\
\hline \hline Typh. P. & Latitude and Longitude \\
\hline 1 & between $30^{\circ} \mathrm{N}$ and $35^{\circ} \mathrm{N}$ and to the west of $130^{\circ} \mathrm{E}$ \\
3 & to the north of $30^{\circ} \mathrm{N}$ and to the west of $130^{\circ} \mathrm{E}$ \\
4 & to the north of $30^{\circ} \mathrm{N}$ and to the west of $131^{\circ} \mathrm{E}$ \\
5 & to the north of $30^{\circ} \mathrm{N}$ and to the west of $131^{\circ} \mathrm{E}$ \\
6 & to the north of $30^{\circ} \mathrm{N}$ and to the west of $132^{\circ} \mathrm{E}$ \\
7 & to the north of $30^{\circ} \mathrm{N}$ and to the west of $133^{\circ} \mathrm{E}$ \\
8 & between $30^{\circ} \mathrm{N}$ and $34^{\circ} \mathrm{N}$ \\
9 & between $30^{\circ} \mathrm{N}$ and $34^{\circ} \mathrm{N}$ \\
10 & between $30^{\circ} \mathrm{N}$ and $34^{\circ} \mathrm{N}$ \\
11 & to the north of $30^{\circ} \mathrm{N}$ and to the west of $131^{\circ} \mathrm{E}$ \\
12 & to the north of $30^{\circ} \mathrm{N}$ and to the west of $127^{\circ} \mathrm{E}$ \\
13 & between $30^{\circ} \mathrm{N}$ and $34^{\circ} \mathrm{N}$ \\
\hline
\end{tabular}

\section{Estimation OF THE SMOOthed Damage LenGth USING THE EWE METHOD}

The damage length for each coast is defined as a summation of the damage length of part of the maritime structures damaged by each typhoon on the coast. Smoothed damage length is further defined as in (2).

$$
L_{s}=\left(L_{d} / L_{t}\right) \times 100
$$

where $\mathrm{L}_{\mathrm{s}}$ is the smoothed damage length, $\mathrm{L}_{\mathrm{d}}$ is the damage length by each typhoon for the coast and $\mathrm{L}_{t}$ is the total damage length by all typhoons for this particular coast. The smoothed damage length indicates the contribution to the total damage length for the coast by each typhoon.

The smoothed damage length is expected to increase rapidly with the increase of maximum wind speed (Hashimura, 2003). To express this trend, a relation between them was given by (3).

$$
L_{s}=\exp \left[\left\{\left(V_{\max }-\mathrm{m}\right) \ln 10\right\} / 10\right]
$$

where $V_{\max }$ is the maximum wind speed near the center of a typhoon, and $\mathrm{L}_{\mathrm{s}}$ is the smoothed damage length. The value of $\mathrm{m}$ was selected to be equal to the minimum values of maximum wind speed in $\mathrm{m} / \mathrm{s} 17,25,29,33,37,41$ and 44 .

Fig. 5 shows a relation of the maximum wind speed near the center and the equivalent wave energy of 74 typhoons. Applying regression analysis to Fig. 5, we get

$$
V_{\max }=10.36 E^{0.123}
$$

Substituting (4) into (3) yields:

$$
Z=\exp \left[\left\{\left(10.36 E^{0.123}-\mathrm{m}\right) \ln 10\right\} / 10\right]
$$

The horizontal axis, E, in Fig. 6 shows the equivalent wave energy of a typhoon. The vertical axis shows the smoothed damage length. The smoothed damage length by each typhoon at each coast is plotted with different symbols for different coasts. The lines a $\sim$ in Fig. 6 are expressed by (5) with $\mathrm{m}$ values from 44 to 17 respectively. The figures shown along the horizontal and vertical axes are the numbers of six areas (from 1 to 6 ) divided by the lines $\mathrm{b} \sim \mathrm{f}$.

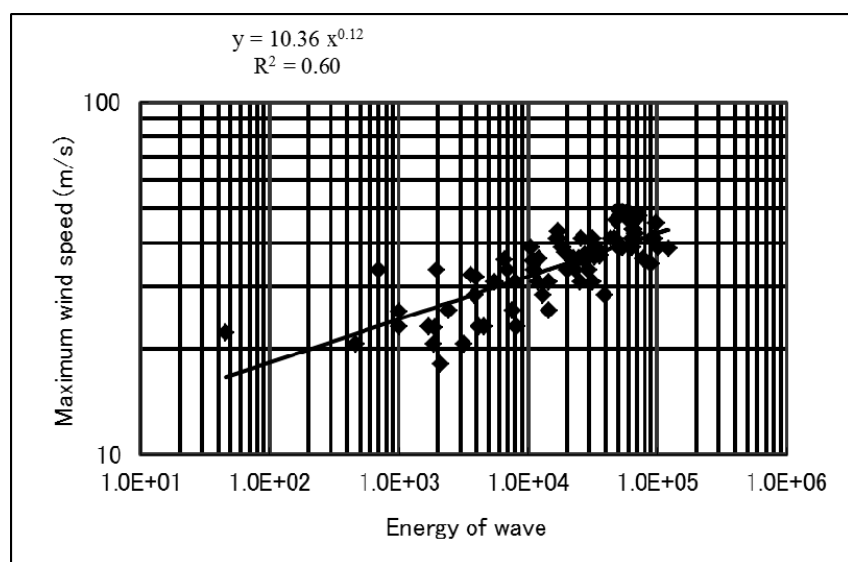

Fig. 5. Equivalent wave energy of typhoons and maximum wind speeds.

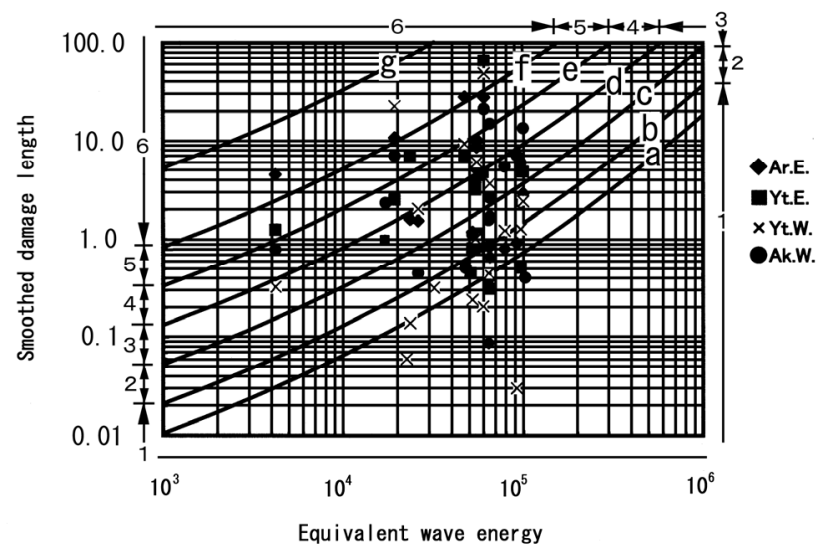

Fig. 6. Equivalent wave energy and smoothed damage length.

\section{SEnSitivity at Four COASTS AND Estimation OF DAMAGE LENGTH}

The first row of the third to sixth and the ninth to twelfth column in Table II indicates 4 coasts in Fig. 2 with their abbreviations. The order of typhoons in the same path depends on firstly the maximum wind velocity near the center of a typhoon at a latitude of $30^{\circ} \mathrm{N}$, and secondly on the depth of the central pressure. Table 2 shows the No. of the area in which the plotted point is located for each typhoon in each path. When no damage occurs, the No. is not shown. The larger the No., the relatively larger damage occurs for the same equivalent wave energy. We call the number in Table II 
the "sensitivity value" of each coast for each typhoon. The sensitivity value indicates the vulnerability of each coast for each typhoon. It should be noticed that the typhoon indicating the maximum smoothed damage length at the coast does not always have the maximum sensitivity value.

TABLE II-I: Sensitivity VALUE OF COASTAL REgIONS FOR EWE OF

\begin{tabular}{|c|c|c|c|c|c|}
\hline Typh. No. & P. No. & Ar. E. & Yt. E. & Yt. W. & Ak. W. \\
\hline T0314 & 1 & & & & \\
\hline T8520 & 1 & & & & \\
\hline T8118 & 1 & 1 & & 1 & 3 \\
\hline T8705 & 1 & & & & \\
\hline T8613 & 1 & & & & \\
\hline T9711 & 1 & & & & \\
\hline T0014 & 1 & & & & \\
\hline T0415 & 1 & & & & \\
\hline T9809 & 1 & & & & \\
\hline T9429 & 1 & & & & \\
\hline T8605 & 1 & & & & \\
\hline T9007 & 1 & & & & \\
\hline T8712 & 2 & 2 & 1 & 3 & 5 \\
\hline T9109 & 2 & 2 & 1 & 1 & 3 \\
\hline $\mathrm{T} 8410$ & 2 & 1 & & 2 & 3 \\
\hline T0306 & 2 & & & & \\
\hline T0006 & 2 & & & & \\
\hline T9119 & 3 & 4 & 2 & 4 & 4 \\
\hline T0418 & 3 & 6 & 4 & 4 & \\
\hline T8105 & 3 & & & & \\
\hline T9918 & 4 & 5 & 6 & 6 & 5 \\
\hline T9117 & 4 & 3 & & 3 & 2 \\
\hline T9708 & 4 & & & & \\
\hline T9210 & 5 & & & 1 & \\
\hline T9612 & 5 & 4 & 3 & 2 & 3 \\
\hline T9019 & 6 & & 1 & & \\
\hline T9313 & 6 & 2 & 3 & 1 & \\
\hline T8019 & 6 & & & & 1 \\
\hline T0416 & 6 & 1 & & & 1 \\
\hline T0423 & 6 & & & & 4 \\
\hline T0310 & 6 & & & & \\
\hline T0406 & 6 & & & & \\
\hline T9719 & 6 & 2 & 2 & 1 & 2 \\
\hline T9020 & 6 & & & & \\
\hline T8922 & 6 & & & & \\
\hline T8506 & 6 & & & & \\
\hline T9514 & 6 & & & & \\
\hline
\end{tabular}

Roughly speaking, the coasts facing the closed sea areas from the number shown in Table II are easily damaged by typhoons in paths No. 3, 4, 8 and 11, and the coast facing the open sea are easily damaged by typhoons in paths No. 4 and 8.

Table III shows the maximum sensitivity value for each path in each coast. This table indicates an index of vulnerability of each coast for each typhoon path. The damage length induced by a coming typhoon at a coast can be estimated as follows:

The path is determined based on Fig. 4 when the typhoon passes through at latitude of $30^{\circ} \mathrm{N}$. The maximum sensitivity value for this path is determined at each coast based on Table III. The maximum and minimum values of the smoothed damage length are determined in Fig. 6 by giving the equivalent wave energy and the maximum sensitivity value. The maximum and minimum damage length by this typhoon at this coast is forecasted by substituting the maximum and minimum values of smoothed damage length and the total damage length by all 74 typhoons at this coast in (2).

\begin{tabular}{cccccc} 
TABLE II-II: SENSITIVITY VALUE OF COASTAL REGIONS FOR EWE OF \\
\hline \multicolumn{5}{c}{ TYPHOONS } \\
\hline \hline Typh. No. & P. No. & Ar. E. & Yt. E. & Yt. W. & Ak. W. \\
\hline T0421 & 6 & 3 & 5 & 1 & \\
T0207 & 6 & & & & \\
T0404 & 6 & & & & \\
T9021 & 6 & & & & \\
T9810 & 6 & & & & \\
T8917 & 6 & & & & \\
T8608 & 6 & & & & \\
T0204 & 6 & & & & \\
T9307 & 7 & 1 & & & 3 \\
T9503 & 7 & & & & \\
T9306 & 7 & & & & \\
T8513 & 8 & 6 & 4 & 6 & 5 \\
T9606 & 9 & & & & \\
T8213 & 9 & & & & \\
T8013 & 9 & & & 1 & \\
T8219 & 9 & & & & \\
T8906 & 9 & & & & \\
T9305 & 9 & & & & \\
T8310 & 10 & 2 & 3 & 2 & 4 \\
T8911 & 11 & 1 & & 1 & 2 \\
T0215 & 11 & & & & \\
T8407 & 11 & & & & \\
T9414 & 11 & & & & \\
T8508 & 11 & & & & \\
T9112 & 11 & & & & \\
T0209 & 11 & & & & \\
T9905 & 11 & & & & \\
T8110 & 11 & 6 & 5 & 3 & \\
T0211 & 11 & & & & \\
T9908 & 11 & & & & \\
T9113 & 11 & & & & \\
T0410 & 12 & & & & \\
T9211 & 12 & & & & \\
T9407 & 13 & & & & \\
T0304 & 13 & & & & \\
T9209 & 13 & & & & \\
T8512 & exclude & & & & \\
\hline \hline
\end{tabular}

TABLE III: MAXIMUM SENSITIVITY VALUES OF EWE FOR EACH REGION

\begin{tabular}{cccccccc}
\hline \hline Path No. & 1 & 2 & 3 & 4 & 5 & 6 & 7 \\
\hline Ar. E. (Closed) & 1 & 2 & 6 & 5 & 4 & 3 & 1 \\
Yt. E. (Closed) & 0 & 1 & 4 & 6 & 3 & 5 & 0 \\
Yt. W. (Closed) & 1 & 3 & 4 & 6 & 2 & 1 & 0 \\
Ak. W. (Open) & 3 & 5 & 4 & 5 & 3 & 4 & 3 \\
\hline \hline Path No. & 8 & 9 & 10 & 11 & 12 & 13 & \\
\hline Ar. E. (Closed) & 6 & 0 & 2 & 6 & 0 & 0 & \\
Yt. E. (Closed) & 4 & 0 & 3 & 5 & 0 & 0 & \\
Yt. W. (Closed) & 6 & 1 & 2 & 3 & 0 & 0 & \\
Ak. W. (Open) & 5 & 0 & 4 & 4 & 0 & 0 & \\
\hline \hline
\end{tabular}




\section{CONCLUSIONS}

The damage length of maritime structures on 4 coasts in the west of Kyushu Island in Japan by typhoons from 1980 to 2004 is analyzed.

The equivalent wave energy of a typhoon is defined and calculated for 74 typhoons attacking these coasts during this period. The vulnerability of the 4 coasts for 13 groups of typhoon with different paths is estimated as sensitivity. This sensitivity value can be used to forecast the damage level at each coast by a coming typhoon. The improved Equivalent Wave Energy (iEWE) method shows high accuracy compared with the current Equivalent Wave Energy (EWE) method.

The improved maximum wind speed method is the easiest way of predicting the vulnerability of a coast with a certain degree of accuracy. The improved Magnitude method is a forecasting method that can take account of the effects of storm surges. Although this method can be expected to improve the accuracy of prediction, it should be considered that the degree of ease of use decreases with improving accuracy. The improved Equivalent Wave Energy (iEWE) method delivers the highest accuracy of these three methods, because it considers the maximum wind speed and the duration of a typhoon. However, the problem remains that the method is quite difficult to use.

This paper shows that the degree of risk and influence of coasts due to typhoon can be estimated by the iEWE method before a typhoon strikes.

Further study including other factors of typhoon is needed for high quality forecasting.

\section{ACKNOWLEDGMENT}

I would like to thank Prof. K. Takikawa of Kumamoto University and Prof. emeritus T. Sakai of Kyoto University for their very helpful advice. I am also grateful to the staff of all the public offices of the prefectures, cities, towns, and land divisions surveyed, who provided data on Kumamoto and Nagasaki Prefectures, and to the members of the Kumamoto Meteorological Observatory of the Japan Meteorological Agency for their cooperation.

This work is supported by JSPS KAKENHI Grant Number 17510153.

\section{REFERENCES}

[1] R. Hashimura, "A study of forecasting method on damage level of maritime structures caused by typhoons," in Proc. 5th International Conference on Hydro-Science and Engineering, IAHR, pp. 1-9, 2002.

[2] R. Hashimura, "Forecasting method of damage length of maritime structures caused by typhoons," The $30^{\text {th }}$ IAHR Congress Prodeedings, Theme A Coastal Environment: Processes and Integrated management, pp. 505-512, 2003.

[3] R. Hashimura, "Forecasting of damage of maritime structures caused by typhoons based on magnitude method," in Proc. International Conference on Port and Maritime R\&D and Technology, vol. 2, pp. 165-171, 2003.

[4] R. Hashimura, "Forecasting of damage length of maritime structures caused by typhoons based on magnitude method," in Proc. $5^{\text {th }}$ International conference on Hydro-Science and-Engineering, IAHR, CD-ROM, pp. 9, 2004

[5] R. Hashimura, "Forecasting of Damage of Maritime Structures Caused by Typhoons Based on Equivalent Wave Energy Method," in Proc. Conference on Solutions to Coastal Disasters 2005, ASCE, pp. 1-10, 2005.

[6] R. Hashimura, "Forecasting of damage length of maritime structures caused by typhoon based on improved MWS method," International conference on Enviroment Informatics-ISEIS'2007, pp.1-9, 2007.

[7] R. Hashimura, "Forecasting of damage of maritime structures caused by typhoons based on improved MWS method," in Proc. 12th International Conference of International Association for Computer Methods and Advances in Geomechanics IACMAG 2011, pp. 2992-2997, 2008.

[8] R. Hashimura, "Forecasting of Damage Level of Maritime Structures Caused by Typhoons Based on Improved Magnitude Method," in Proc. 9th International Conference on Hydro informatics HIC 2010, IAHR, pp. 1170-1177, 2010.

[9] Y. Goda, Random Seas and Design of Maritime Structures, University of Tokyo Press, pp. 323, 1985.

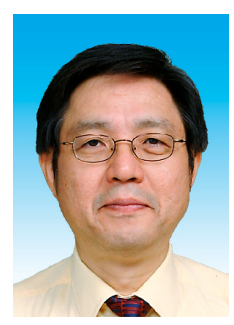

Dr. Ryusuke Hashimura is an associate professor in the department of EcoDesign at Sojo University, in Japan. He completed his Bachelor degree in the field of Civil Engineering from the Kumamoto Institute of Technology (now, Sojo University), Japan. He also completed his Dr. Eng. in New Frontier Science at Kumamoto University in Japan. He has about 40 years research and teaching experience in Department of Civil Engineering and also in Department of EcoDesign at Sojo University.

His research interests are mainly in hydraulics, coastal environmental engineering and natural disaster science especially in storm water management, damage forecasting, groundwater engineering and climate change impacts etc. He has issued more than 130 papers in International and National Journals and Conferences. $\mathrm{He}$ is a member of Asia-Pacific Chemical, Biological \& Environmental Engineering Society (APCBEES), JSCE (Japan Society of Civil Engineers), ASCE (America Society of Civil Engineers), IAHR (International Association for Hydro-Environment and Research) etc. 